\title{
Influência emocional como estratégia na gestão de marcas
}

\section{Emotional influence as branding strategy}

BARAÚNA, Graziele; Universitária; Universidade da Região de Joinville Univille

grazi_barauna@hotmail.com

SILVA, Elcio Ribeiro da; Mestre; Universidade da Região de Joinville Univille

e.ribeiro@univille.br

MARCHESINI, Bernardo Linhares; Especialista; Universidade da Região de Joinville Univille bernardo@rmsadv.com.br

\section{Resumo}

O presente trabalho visa apresentar as pesquisas realizadas durante o ano pelo Projeto Gbrand, que estuda novos métodos utilizados na gestão de marcas e novas abordagens, como o Design de Serviço e o Design Thinking. Será apontado também, o comportamento neurológico das pessoas e como este é influenciado, mesmo que inconscientemente, quando impactado por alguma propaganda ou estratégia de marketing. Assim, o presente artigo tem como escopo, mostrar como as grandes empresas estão utilizando ferramentas para fidelizar, cada vez mais, seus clientes por meio da influência emocional. O objetivo do Gbrand é encontrar novos métodos e abordagens no marketing, já que o aumento da tecnologia fez crescer o consumo e, consequentemente, a competitividade, gerando novas formas de chamar a atenção do público, seja em redes sociais, sites, comerciais, entre outros.

Palavras Chave: Gestão de marcas, Emoção, Ferramentas e Abordagens.

\section{Abstract}

The present artcile intend to show the researches made along the past year by Gbrand, wich study new methods useds in branding management e new approaches, like Service Design and Design Thinking. Will be pointed, also the neurological behavior of people and how it is influenced, even unconsciously, when under some advertise or marketing strategy. So, this article aims to demonstrate how big companies are using some tools to bring their costumers even closer, by the emotional influence. The goal of Gbrand is to find new methods and approaches in marketing, because the technology increase made de consumism grow and, consequently, the competitivity, generating new ways to get public atention in social media, sites, adds, and others.

Keywords: Brand mangement; Emotion; Tools and Aproaches. 


\section{Introdução}

Segundo Brown (2017) o atual cenário econômico brasileiro tem exigido das empresas cada vez mais velocidade de adaptação. A concorrência é cada vez maior e o público mais exigente. É nesse cenário que a experimentação ganha bastante relevância, pois com isso, a empresa dá um grande passo em direção a diminuir riscos de insucesso e aumenta consideravelmente suas chances de causar um impacto maior na vida das pessoas com a solução final. Assim, as companhias não devem focar em perseguir o termo inovação, mas sim, buscar relevância pela criação de uma cultura de empatia, cocriação e constante experimentação. "O design não é uma simples resposta, é a chave para as perguntas corretas". (Brown, p. 3, 2017). Destarte, este artigo apresenta métodos e abordagens para conquistar esse novo público, trazendo significado aos produtos da marca. Gerando assim, uma relação afetiva entre o cliente e a empresa

\section{Gestão de Marcas}

Um produto é inovador quando ele causa impacto na vida das pessoas e transforma para sempre a forma de essas pessoas viverem, afirma Brown (2017). Nenhuma empresa mais discorda que buscar a constante inovação e criatividade será o caminho de sobrevivência e diferenciação nos próximos anos. Porém inovação não é algo que se percebe ao se criar, e sim, como dito pelo autor, quando se nota a transformação na vida das pessoas. Diante deste quadro é que se apresentam novos métodos de Design e seus resultados positivos na criação de produtos ou serviços, bem como na solução problemas existentes durante o processo.

\subsection{Design de Serviço:}

Marc Fontijn apud Hayhow (2014) afirma que "quando se tem duas cafeterias, uma ao lado da outra, vendendo exatamente o mesmo café pelo exato mesmo preço, é o design de serviço que vai fazer com que o consumidor entre em uma e não na outra". Assim, conforme Hayhow (2014) explica, um design de serviço de qualidade é composto, também, por uma série de experiências de branding, que levam o usuário a escolher entre produtos e serviços. O design de serviço procura facilitar e surpreender a experiência do cliente com a marca. Em uma entrevista para o SEBRAE Nacional (2017), Luis alt afirma que tudo começa por entender o cliente e suas necessidades, pois com empatia, colaboração e experimentação, grandes empresas ou pequenos empreendedores podem oferecer experiências realmente relevantes para seus usuários. O Design de serviço é de extrema importância segundo Melo (2016), já que não é possível oferecer um produto sem oferecer também um bom serviço ou atendimento. Melo (2016) afirma ainda que a lealdade do consumidor ou do cliente está no serviço e atendimento, e não necessariamente na tecnologia. Mesmo que a pessoa tenha gostado do produto adquirido da empresa, ele não voltará a consumir seus produtos se foi mal atendido. Entretanto, se o serviço, a comunicação e o atendimento o surpreenderem, ele não somente retornará a comprar seus produtos, como também, indicará essa empresa positivamente aos outros.

É fundamental que ao ler o presente artigo se tenha em mente que quando se utiliza a palavra produto, está-se referindo a tal como gênero, sendo espécies, bens e serviços. Não se pode mais dissociar produto de serviço, sendo que uma empresa que fornece seu serviço, tem esse como seu produto, da mesma maneira que aquela que apresenta um bem a ser consumido.

\subsection{Design Thinking:}

Surgiu para solucionar problemas, assim como criar produtos inovadores obtendo a interação com o usuário durante o processo. Segundo um estudo da Nielsen (2014), 76\% dos 
novos lançamentos no grande consumo fracassam no primeiro ano de vida. Isso acontece, pois as pessoas estão cada vez mais exigentes. Com essa abordagem, aumentam-se as chances do produto se adequar bem ao mercado, pois, ainda, utiliza o conhecimento de vários profissionais, que de maneira empática cocriam dentro desse cenário transdisciplinar. Desse modo, o principal objetivo do Design Thinking é colocar as pessoas no centro do desenvolvimento de projetos, fazendo com que os participantes fiquem imersos, resolvendo problemas complexos de forma criativa, inovadora e focada nas necessidades do mercado (VIEIRA, 2017). O Design Thinking é uma abordagem feita em grupo, permitindo assim um olhar para o problema por diversos pontos de vista, gerando uma quantidade maior de ideias e soluções, constatando assim que não existe mais um só dono da verdade (VIEIRA, 2017). Destarte, o primeiro passo é a escolha dos participantes dessa abordagem. Segundo Vieira (2017) o ideal é ser um time heterogêneo (sociólogos, arquitetos, designers, médicos e clientes - por exemplo) para que se observe o problema por vários prismas distintos. Após, a metodologia é dividida em 4 etapas:

1. Imersão: É a coleta de informações, pesquisas, dados, procurar novas perspectivas;

2. Análise: É a fase que organiza os dados coletados na fase anterior. Geralmente, utiliza-se post-its para sintetizar todas as informações coletadas.

3. Ideação: É nessa etapa que são usadas técnicas para a geração de ideias ao tema do projeto.

4. Prototipagem: É a fase na qual as ideias geradas podem ser validadas e verificadas.

Em uma entrevista para a Endeavor Brasil, Guilherme Neumann, head de Design do Nubank, contou como colocam o design como prioridade e, por conta disso, a startup cresce em ritmo exponencial. Segundo Guilherme (2017) o Nubank surgiu utilizando o Design Thinking para criar um banco totalmente diferente dos outros, em que, em vez do serviço tradicional oferecido pelos bancos, fosse oferecida uma experiência para seus clientes, sendo uma relação humanizada e com mais empatia. Colocando o design no centro da estratégia de negócios, o Nubank busca facilitar, a experiência do cliente com o banco, otimizando assim uma das prioridades do cliente: o tempo. O Nubank abraçou a principal tendência de consumo da atual Era: compram-se experiências, e não produtos. Neumann enfatiza que para solucionar necessidades reais dos usuários, estes precisam participar do processo. Por isso, a Nubank convida semanalmente pessoas para testar seus produtos e opinar sobre eles. Guilherme contou que uma das oportunidades de negócio criadas com o Design thinking foi permitir a antecipação de parcelas para o cliente, gerando até descontos para os clientes pela adesão ao programa. Mesmo com todo o processo de ideação e validação, eles não conseguiram antever o sucesso da solução. Porém hoje, segundo ele, é uma das funções mais amadas pelos usuários. É por esse diferencial: de colocar o Design em todo o processo, que o Nubank em apenas 3 anos de existência já possui mais de 7 milhões de clientes e tem uma fila de espera de quase 500 mil pessoas.

\subsection{Co-marketing:}

Segundo Lima (2016) co-marketing é uma forma de marketing de relacionamento, que permite que as empresas trabalhem juntas em uma campanha, beneficiando-se mutuamente. Lima (2016) relata que há 3 (três) razões principais para iniciar uma parceria de co-marketing. A primeira é atingir um público novo, pois elas podem utilizar seu banco de contatos para introduzir a marca do parceiro, aumentando exponencialmente seu alcance. Segundo é obter conhecimentos adicionais sobre algo que a empresa não domine. $\mathrm{E}$, por último, reduzir os custos pela metade e dobrar o poder do impacto promocional. Em 2017, um dos grandes exemplos de sucesso no co-marketing foram as parcerias feitas pela artista, Anitta. Sua rápida ascensão foi 
resultado de uma estratégia de marketing exemplar, que fez seu nome ser conhecido mundo afora. Segundo Sampaio (2017) Anitta é a única brasileira no Social 50 da Billboard americana, um ranking que mede a popularidade de artistas nas redes sociais, aparecendo inclusive na frente da Beyoncé (30) . "No Youtube, seus vídeos oficiais somados aos enviados pelos fãs registram 2,5 bilhões de views. No Spotify, é a quarta mulher mais ouvida desde que o aplicativo foi lançado no Brasil." (Sampaio, 2017). Os números e o sucesso da cantora não param de crescer, e isso é devido as ações de marketing feita por ela e suas parcerias. Foram 7 singles em menos de um ano, com parcerias feitas com Maluma, Pabllo Vittar, entre outros. Anitta se mostra versátil, pois faz parcerias em vários estilos musicais, conseguindo assim ser escutada por um público diferente do seu. Anitta começou buscando notoriedade em território nacional, fazendo inúmeras parcerias como Luan Santana, Nego do Borel, tendo assim, maior público e views. Após isso, ela adentrou no mercado latino, mostrando sua ecleticidade ao fazer parcerias com o Maluma e J Balvin no estilo reggaeton. Com o sucesso dessas parcerias, Anitta realizou outras parcerias internacionais, com Iggy Azalea e Major Lazer, apresentando-se até no programa norte-americano The Tonight Show. Essa estratégia de co-marketing é uma parceria mútua, pois esses outros artistas buscavam se fortalecer também no Brasil. Além dos artistas, Anitta utilizou o co-marketing com empresas do setor alimentício, como no clipe de "Paradinha" que foi feita a parceria com a Cheetos. Daniela Cachich, vice-presidente de marketing da PepsiCo relata na entrevista para Sacchitiello (2017) que, embora a união com a cantora tenha como objetivo estreitar os laços com o público brasileiro, a PepsiCo admite que o gingado de Anitta pode ampliar a visibilidade internacional de Cheetos. "A marca é global e temos uma atuação forte nos Estados Unidos e também em alguns países da América Latina. Claro que com a projeção que ela está tendo faz com que essa ação ganhe projeção em outros países. Imaginamos que o alcance seja global", diz Daniela.

Figura 1 : Clipe "Paradinha" da Anitta

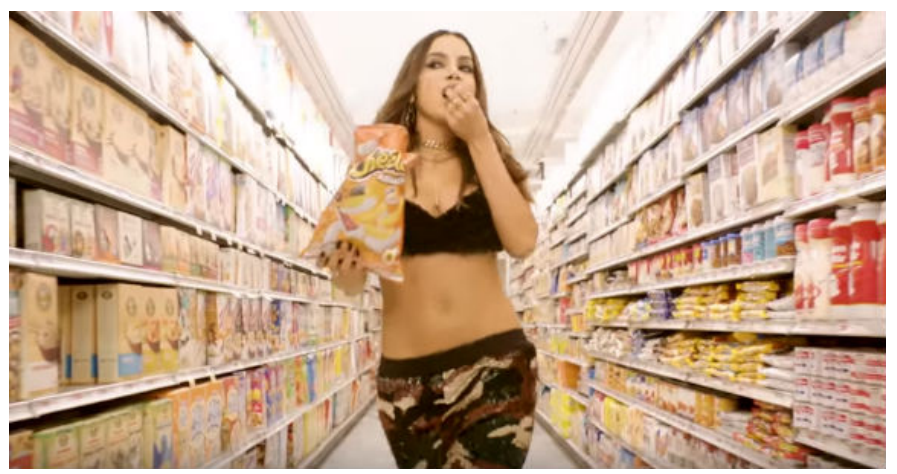

Fonte: Disponível em: <https://goo.gl/RTF3aA>. Acesso em: 13 dez. 2017

Segundo Benvenga, 0 exemplo de Anitta mostra para as marcas que a estratégia de comarketing pode caminhar bem de diferentes formas, pois há um caminho mais natural em que a empresa busca um parceiro dentro do seu ramo de atuação e outra mais ousada, com a captação de parcerias em outros segmentos que tenham potencial de atrair novos públicos com perfil similar às personas já estabelecidas pela marca.

\subsection{Co-branding:}

Já o co-branding ocorre quando é realizado um acordo de marketing em que duas marcas diferentes se unem para criar um produto de ambas identidades, conforme Lima (2016). Em 2016, a nova associação do chocolate Ovomaltine com a "McDonald's" gerou polêmica. Segundo Moraes 
(2016) o milk-shake de Ovomaltine sempre foi um clássico no "Bob's", sendo criado em 1959 por essa rede de fast food. O Ovomaltine no milkshake ajudou a atrair milhares de consumidores, por conta de sua exclusividade, durante seis décadas. Além de ganhos financeiros, essas uniões propiciam a penetração em um novo mercado, melhoria da imagem e expansão do market share. E para que isso ocorra é preciso que as marcas tenham algumas afinidades. "Nossa proposta é oferecer a experiência Ovomaltine para os consumidores em diferentes produtos nas mais diversas categorias e por isso o co-branding é tão importante para a marca. Os nossos parceiros nos ajudam a desenvolver novos produtos, sempre com o sabor e a crocância que são exclusivos e próprios da marca", afirma a Diretora de Marketing do Ovomaltine. Mas, o "McDonald's" buscou essa parceria também. A associação da Ovomaltine teve importância para o McDonald's, que está reestruturando sua linha de milkshake, categoria em que o Bob's sempre teve mais destaque. $O$ Bob's, continuará oferecendo o mesmo produto rebatizado de crocante.

\section{Abordagens Emocionais}

Roger Dooley, especialista em neuromarketing, cita em seu livro Brainfluence que, em $80 \%$ (oitenta por cento) dos casos, tomamos uma decisão antes de ser racionalmente conscientes disso. Assim, as pessoas podem sofrer influências do marketing sem que elas nem percebam. A seguir, seguem as abordagens que influenciam o público emocionalmente, com o objetivo de conquistá-lo e ser lembrado.

\subsection{Storytelling:}

Segundo Xavier (2017), assim como as pessoas, toda marca tem uma história, isso não tem como mudar, porém ela pode ser contada e interpretada livremente por usuários e concorrentes, ou moldada pelos donos da marca. "Marcas têm o direito de criar uma história do zero, elaborar suas lendas e mitos." (Xavier, 2017). Segundo Rez (2017) storytelling é a capacidade de contar histórias utilizando recursos audiovisuais juntamente com as palavras. É um método que promove o seu negócio sem que haja a necessidade de fazer uma venda direta, em outras palavras, o storytelling tem um caráter muito mais persuasivo do que invasivo. Atualmente, o consumidor não busca só o produto. Ele quer se identificar com a marca, com a história que ela conta, buscando assim valores intangíveis na marca. Hoje, conforme Xavier (2017) o storytelling possui importância devido às redes sociais, pois é uma realidade em que todos se tornam geradores de conteúdo e unidades de mídia ao mesmo tempo, estabelecendo assim novas conexões. As histórias dão sentido à vida, pois sustentam valores básicos como: religião e ética além de aspectos culturais. $A$ campanha de natal das lojas Renner de 2017, conta a história de Rita tentando se comunicar com a sua nova vizinha e sendo "ignorada" por ela. Porém, com o tempo Rita percebe que sua vizinha é deficiente auditiva, e assim ela trata de aprender Libras para poder se comunicar com a garota ao recebê-la para o Natal em sua casa. Segundo Alves (2017) a intenção da Renner com esse vídeo é de lembrar as pessoas o que realmente importa no Natal, que é expressar o seu amor de todas as formas. Por emocionar as pessoas, essa campanha foi muito compartilhada nas redes sociais. Esse é um bom exemplo de storytteling, pois campanha não teve a intenção (direta) de vender os produtos da marca, mas sim emocionar as pessoas a partir de uma história que envolva o espectador. Link da campanha: https://goo.gl/3rCsig. Porém, ao emocionar as pessoas e contar uma bela história, ela quer que todos identifiquem sua marca com os valores ali transmitidos, o que de maneira indireta, fará com que as pessoas procurem adquirir seus produtos

\subsection{Storydoing:}

O storydoing vai além de só contar uma história. Como o próprio nome diz, além de contar uma história a empresa tem que fazer algo. Segundo Frota (2016) esse conceito mostra que, às 
vezes, contar histórias não é o suficiente, é preciso vivenciar, mostrar os efeitos e ações de suas campanhas. Conforme Francucci (2016) no storydoing, a narrativa não nasce no fim de todo o processo, mas, pelo contrário, é o começo de tudo. Não é apenas um posicionamento de comunicação, e sim um propósito, uma causa, uma razão de existência para a marca. Com a definição desse propósito autêntico a história se materializa não mais pelas palavras e imagens de uma campanha, e sim por meio de inovações icônicas, como: um novo produto, um novo serviço, um novo modelo de distribuição, novos formatos de comercialização, novos procedimentos etc. Essas inovações fazem com que a construção da marca aconteça a partir do que a empresa faz e não a partir do que ela diz. Assim, o storydoing traz mais credibilidade à companhia. Segundo a Agência Mzclick (2016) para a técnica do storydoing a história precisa ser sobre um projeto ou uma ambição para tornar o mundo melhor ou para melhorar a vida dos menos favorecidos. Recentemente, a Skol resolver mudar sua "imagem" machista construída reiteradamente por suas antigas propagandas. Campanhas que tratavam mulheres como objeto e as colocavam a serviço dos homens. Segundo Almeida (2017) essa campanha foi lançada no mês das mulheres - Março de 2017 - e a Skol quis mostrar que também evoluiu, deixando sua cultura machista para trás. A empresa convidou 8 (oito) ilustradoras engajadas em questões feministas para recriar os antigos anúncios e os resultados demonstram enorme êxito. A campanha "Reposter" - que tem o slogan "redondo é sair do seu passado" - além de dar um novo visual para as antigas peças e fugir do estereótipo sensualizado da mulher, reforçou o poder feminino. Ainda no site, a Skol deixou disponível um espaço para o público recriar um post e enviar a eles. Storydoing é isso. É mais do que contar uma história, é criar e fazer essa história, para criar a identidade as sua marca, ou mudar os erros do passado com ações que melhorem a sociedade. Link da campanha: https://goo.gl/GpzxiS

\subsection{Arquétipos:}

Segundo Couto (2004), quando uma pessoa percebe um arquétipo, determinados neurotransmissores são produzidos, gerando emoções. Muitas vezes a pessoa não tem a menor ideia da influência que está recebendo daquele arquétipo. Quando este está associado a um produto, a pessoa associará aquelas emoções a este produto. Isso se chama de neuroassociação, e segundo Couto (2004) toda a percepção ocorrida num determinado momento será armazenada conjuntamente. Assim, segundo Mark e Pearson (2001), os produtos atraem as pessoas porque corporificam um arquétipo. A seguir, os 12 arquétipos:

1. Arquétipo "O Inocente": Bondade, Amor, Fraternidade e Pureza são elementos-chave para este perfil, segundo Barony (2017). Quem busca esse arquétipo quer vivenciar a própria personalidade sem rótulos e nem preocupações da vida moderna. A fé e otimismo constroem um forte laço com este arquétipo, o qual tem a tendência de fazer tudo o mais correto possível. Muitas marcas fazem uso do arquétipo como: Johnson\&Johnson (principalmente a linha Johnson's baby), marcas de produtos de limpeza (Veja, Omo, entre outros) e marcas de higiene (Ivory, Dove, etc).

2. Arquétipo "O Herói": Dinâmico, veloz e ágil: é assim o público que esse arquétipo busca atingir. Assim, conforme Wibowo (2017) as marcas que pretendem explorar esse tipo de arquétipo precisam oferecer produtos que estejam ligados às aptidões e competências ou que ofereça desafios ligados ao perigo e à velocidade. $\mathrm{O}$ arquétipo de Herói conta uma história de conquista, sucesso e superação. E como toda história de heroísmo, possui também o vilão. Esse vilão geralmente é um fator externo, mas a Nike posicionou com maestria o vilão como um fator interno do seu público, como a preguiça, comodismo e cansaço. A Nike é a principal empresa que utiliza esse arquétipo para contar sua história e para o seu marketing. Transformar qualquer um 
em um "atleta" reforça a constante luta interna que todos experimentam quando enfrentam suas respectivas questões físicas, independentemente do gênero, raça ou cultura. A publicidade da Nike é um dos exemplos de marca emocional mais efetivos no mundo do marketing hoje. A fidelidade de seus clientes está fora dos gráficos, tudo graças à estratégia da marca Nike e à aplicação magistral da marca emocional. A estratégia da marca Nike é excelente porque mostra que podemos ser nossos próprios heróis ou inimigos, que depende de cada um. De uma maneira ou de outra, somos todos heróis de nossa própria história, e a Nike Market já identificou esse sentimento - e a usou para inspirar a fidelidade atemporal do cliente.

3. Arquétipo “O Amante": Segundo Barony (2017) este arquétipo está fortemente associado a diversas marcas, principalmente no universo da moda e da beleza estética. Caracteriza-se pelo culto ao belo e pela valorização do romance e do sexo, através da invocação de tudo o que manifeste a atração física e a admiração corporal. O Amante evoca também a elegância, o lúdico e o erótico além de diversos prazeres efêmeros. Os clientes do Arquétipo "Amante" compram os produtos pela aparência e pelo luxo que vão representar usando ou postando nas redes sociais. Personalidades como Marilyn Monroe e Kim Kardashian são exemplos desse arquétipo no Auto Marketing. E as marcas que utilizam o arquétipo de Amante são: Victoria's Secret, L'OREAL, Playboy e Coco Chanel.

4. Arquétipo "O Fora da Lei": Segundo Lindsay (2015) o Fora da lei foge do senso comum e busca profundamente revolução, liberdade e símbolos de mudança. Alguém rebelde, selvagem, que quebra todas as regras. O público desse arquétipo se vê em um mundo no qual ele mesmo faz as regras, deseja vingança ou então revolução. A liberdade e a independência são palavras de ordem para esse personagem. Geralmente a meia idade ou adolescência são períodos da vida com grandes conflitos na família e na sociedade, assim as marcas que vendem para este público usam, muitas vezes, esse arquétipo para levarem ao seu público a autonomia que tanto almejam. Um executivo da empresa Harley Davidson, disse em uma entrevista que: "O que vendemos é a oportunidade de um contador de 43 anos se vestir de couro preto, sair de moto por aí e ver as pessoas com medo dele". É esse espírito de rebeldia que as empresas buscam proporcionar ao seu público utilizando esse arquétipo. Marcas do Arquétipo Fora-da-Lei: Harley Davidson, MTV e Apple.

5. Arquétipo "O Bobo da Corte": Conforme Barony (2017) trata-se de um arquétipo muito verdadeiro, que não está preocupado em se esconder no grupo. Ele quer ser aceito do jeito que ele é, espontâneo e brincalhão. Esta é sua maneira de encarar a vida. O bobo da corte nos ajuda a tornar situações chatas menos pesadas e densas, não levando a vida tão a sério e trazendo um pouco de descontração. Seu espírito alegre e descompromissado permite que a inovação e a informalidade descompliquem as tarefas diárias, muitas vezes tediosas. No marketing: o Bobo da Corte é o arquétipo perfeito para as marcas de cerveja. Os comerciais de cerveja, que costumam ser divertidos e espirituosos, demonstram bem a similaridade com este arquétipo. Por exemplo, o "ritual" de sair para beber cerveja é normalmente envolvido por um clima de descontração e despreocupação. Um ambiente sem pressões em que todos são semelhantes, aceitos como são e onde a cerveja é o grande nivelador. Este é o ambiente ideal para o Bobo da Corte, e portanto, ele é o arquétipo preferido da categoria de cervejas. Marcas que utilizam esse arquétipo: Skol, McDonald's, Pepsi, Havaianas, Fanta, etc.

6 - Arquétipo "O Criador": Criar algo novo é o lema, pois se algo não existe pode ser construído, afirma Lindsay (2015). Este tipo de personagem tem como aliados a criatividade e imaginação, sempre inovando em algo duradouro e evitando a mediocridade na hora de elaborar uma grande 
sacada. O criador é impulsionado pelo seu desejo de produzir obras excepcionais e duradouras, e eles têm muito medo da mediocridade. Os clientes criadores evitam publicidade em geral, mas podem desfrutar de anúncios experimentais, limitantes ou inovadores. Os tipos de criadores são uma categoria difícil de atrair, mas as marcas de criadores bem-sucedidas geralmente desenvolvem uma base de fãs devotada. O criador canaliza seus problemas, dificuldades e os utiliza como uma válvula de escape. Se sente sempre compelido a criar e inovar. As marcas criadoras prometem autenticidade e inovação. Como, por exemplo, a Apple que tem a identidade da marca criadora pregada. Criaram e criam produtos que fazem seus clientes refletir em como foi possível viver até ali sem aquele produto. Marcas que utilizam esse arquétipo: Apple, Google, Lego, Netflix.

7. Arquétipo "O Governante": Segundo Junior (2014) o governante sempre está no comando de tudo, ele é sempre quem administra muitas responsabilidades importantes. O controle, poder, revolução e liderança pertencem a este arquétipo. Apesar de ser alguém responsável e com muito peso nas costas, precisa liderar, ter o comando. No marketing, pode ser associado a marcas que reforçam atributos de liderança e prestígio, reafirmando que o cliente está no poder. Geralmente utilizado por empresas do setor financeiro, cartões de crédito e automobilística. Exemplos: Porto Seguro, Mercedes-Benz, American Express.

8. Arquétipo "O Prestativo": O Prestativo é um altruísta, movido pela compaixão, pela generosidade e pelo desejo de ajudar os outros, afirma Junior (2014). Ele teme a instabilidade e a dificuldade, não tanto por si mesmo, mas pelo impacto social. No marketing, ele é associado a prestação de serviços que se preocupa com os outros. As empresas que adotam esse tipo de posicionamento têm sempre em seu tom de comunicação, o teor de ajudar os seus consumidores a enfrentar suas dificuldades de forma mais fácil, utilizando seu produto. Exemplos de Marcas que utilizam esse arquétipo: Evernote, Buscapé, Santander.

9. Arquétipo "O Cara Comum": Segundo Barony (2017) o arquétipo do cara comum é tranquilo e gosta de fazer parte de uma multidão, sem expor quaisquer convicções, sendo o companheiro e trabalhador. Possui um perfil democrático e está presente na maioria dos segmentos da sociedade. Tem dons como empatia e baixa vaidade e tem como estratégia nivelar-se utilizando virtudes comuns. "Todo mundo usa" é o lema que a marca Havaianas deixa claro em seus comerciais e slogan que a marca é para todos. Todos são iguais, todos usam e todos querem. Mostrando assim, que todos podem usar havaianas, inclusive personalidades e famosos. Exemplos de marcas com este arquétipo: Cerveja Brahma ("Sou Brahmeiro"), Havaianas.

10. Arquétipo "O Sábio": $O$ arquétipo do sábio tem como dons a inteligência e confiança. Seu maior desejo é alcançar a felicidade através do conhecimento e da verdade, segundo Junior (2017). O Sábio gosta de produtos e marcas que incentivem o intelecto, a criatividade e o raciocínio. Típico de quem é investigador, pensador e vive dando conselhos. Costuma ver o mundo de um jeito diferente, com a ótica do conhecimento. Exemplos de marcas com este arquétipo: Discovery Channel, Itaú, HP, CNN, Google, Ibope, The New York Times.

11. Arquétipo "O Mago": O Arquétipo do Mago faz com que o sonho se torne realidade, afirma Lindsay (2015). O mago quer entender o universo e seu lugar nele, por isso os clientes desse arquétipo precisam sentir que podem se tornar mais sábios ou influenciar as pessoas usando seus produtos. Os anúncios devem ser tão imaginativos e inspiradores quanto possível. As marcas mágicas se promovem como porta de entrada para o conhecimento e a experiência transformadores. Exemplos de Marcas que utilizam esse arquétipo: Disney, Mastercard, Axe. 
12. Arquétipo "O Explorador": Conforme Lindsay (2015),o explorador pode ser relacionado a marcas que incentivam seus consumidores a descobrir novos mundos e a experimentar o novo. A inquietação e a falta de rotina, assim como a independência são essência deste arquétipo. Ele anseia aventura e quer descobrir o mundo por si só, temendo a conformidade e o vazio interno. A geração $Y$ tem muito a ver com este perfil, sendo elas pessoas inquietas e que quebram regras. Os clientes desse arquétipo buscam por marcas que promovem a liberdade e a autodescoberta, especialmente aquelas que convidam o cliente a embarcar em uma jornada com eles. É conhecido por empurrar fronteiras e deliciar-se com descobertas inesperadas, abraçando uma filosofia "sem limite". Exemplos de marcas que utilizam esse arquétipo: Levis, Mc Donalds, Starbucks, Virgin, Nike, Amazon, Jeep, Red Bull.

\section{Conclusão}

O presente estudo, como se pôde observar, buscou trazer em destaque a evolução das ferramentas e abordagens do design e do marketing, que buscam influenciar o consumidor de maneira muito mais profunda e duradoura.

Nota-se, primeiramente que o design tem buscado ir, cada vez mais, ao encontro do usuário, por vezes fazendo ele participar no processo criativo, trazendo para junto de si aquele quem irá, no futuro, utilizar daquele produto. Tal ideia tem se mostrado eficaz, levando a muitas empresas buscarem essas abordagens para projetos cada vez mais impactantes no seu escopo de trabalho.

Na outra ponta, o neuromarketing, trouxe a possibilidade de se influenciar o consumidor de maneira mais contundente, fazendo com que ele, mesmo sem perceber, se torne um cliente e mais, um propagador da marca.

Apresentou-se depois, duas formas de posicionamento de marca que são necessárias e fundamentais hoje, visto que como apontado no texto, toda marca tem sua história, e cabe ao seu detentor tomar as rédeas e escolher qual história quer contar.

Por fim, a evolução das áreas de conhecimento estudadas construíram os 12 arquétipos acima descritos, e tais mostram uma base de abordagem para que as marcas entendam quem irão atingir ao se posicionar de determinada forma.

Logo, este artigo buscou apresentar um mundo novo, mas nem tão novo, de possibilidades que se apresentam para que as empresas e suas marcas saibam explorá-las e se destacar em um mundo tão competitivo como o que vivemos.

\section{Referências}

ALMEIDA, Leticia. Skol lança campanha para o mês das mulheres e legitima o empoderamento feminino. Disponível em: <https://goo.gl/jH6JME>. Acesso em: 13 dez. 2017

ALVES, Soraia. Renner surpreende com comercial de Natal emocionante. Disponível em: <https://goo.gl/3XZfbu>. Acesso em: 13 dez. 2017

BARONY, Jefter. 12 arquétipos de marca que você precisa conhecer. Disponível em: <https://goo.gl/5mFUjW>. Acesso em: 14 ago. 2017

BENVENGA, Flávia. O que Anitta pode nos ensinar sobre co-marketing. Disponível em: <https://goo.gl/wd5AJw>. Acesso em: 13 dez. 2017

BROWN, Tim. Design Thinking - Uma metodologia poderosa para decretar o fim das velhas ideias. Rio de Janeiro: Alta Books, 2017.

COUTO, Hélio. Marketing e Arquétipos. 1 edição. Santo André: Editora: Hélio Couto LTDA, 2004.

DOOLEY, Roger. Brainfluence. New Jersey: John Wiley \& Sons, Inc. 2012. 
FRANCUCCl, Átila. Storydoing $\mathrm{x}$ storytelling, $\mathrm{o} \mathrm{x}$ da questão. Disponível em: <https://goo.gl/rGkopC>. Acesso em: 13 dez. 2017

FROTA, Letícia. Storytelling $x$ Storydoing - $O$ marketing de ir além. Disponível em <https://goo.gl/SK9xCz>. Acesso em: 13 dez. 2017

HAYHOW, Maria. 6 princípios de design de serviços que o ajudarão a atingir seus usuários. Disponível em: <https://http://bit.ly/2ytrcMM>. Acesso em: 14 dez. 2017

HERRERA, Leandro. 5 lições sobre design e experiência para criar produtos marcantes. Disponível em: <https://endeavor.org.br/5-licoes-sobre-design-e-experiencia/>. Acesso em: 07 dez. 2017

JUNIOR, Luiz Antonio Alexandre. 12 arquétipos para a construção de marcas com significado. Disponível em: <https://goo.gl/FKqfNn>. Acesso em: 14 ago. 2017

LIMA, Alexandre Bastos Moreira. Guia prático das novas ferramentas comerciais. Porto Alegre: Bookman, 2016

LINDSAY, Ffion. The 12 brand archetypes all successful businesses are built on. Disponível em: <https://goo.gl/tcy6YX>. Acesso em: 14 ago. 2017

MARK, Margaret; PEARSON, Carol S. O Herói e o Foda-da-Lei: Como construir marcas extraordinárias usando o poder dos arquétipos. São Paulo: Editora Cultrix, 2001.

MELO, Eugênio Bispo. Gestão de Marketing e Branding - a arte de desenvolver e gerenciar marcas. Rio de Janeiro: Alta Books, 2016

MORAES, Roberta. Ovomaltine mostra a força do co-branding, um impulsionador de vendas. Disponível em: <https://goo.gl/EZAzTs>. Acesso em: 11 dez. 2017

SAMPAIO, Pedro. Anitta: um caso de marketing que vale a pena ser estudado. Disponível em: <https://goo.gl/KsYCKz>. Acesso em: 13 dez. 2017

SEBRAE Nacional. Design de Serviços: envolva as pessoas e crie negócios encantadores. Disponível em: <http://bit.ly/2ytFixB>. Acesso em: 14 dez. 2017

VIEIRA, Renato. Como usar o Design Thinking para construir personas de forma colaborativa com a sua equipe. Disponível em: <https://goo.gl/iJoojy>. Acesso em: 24 nov. 2017

XAVIER, Adilson. Storytelling - Histórias que deixam marcas. Rio de Janeiro: Best Business, 2017. 